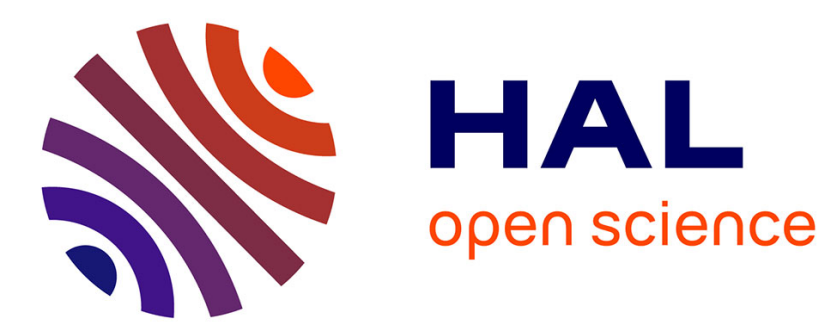

\title{
Pétrographie et géochimie comparées des pellets phosphatés et de leur gangue dans le gisement phosphaté de Ras-Draâ (Tunisie). Implications sur la genèse des pellets phosphatés
}

Aïda Ben Hassen, Jean Trichet, Jean-Robert Disnar

\section{To cite this version:}

Aïda Ben Hassen, Jean Trichet, Jean-Robert Disnar. Pétrographie et géochimie comparées des pellets phosphatés et de leur gangue dans le gisement phosphaté de Ras-Draâ (Tunisie). Implications sur la genèse des pellets phosphatés. Swiss Journal of Geoscience, 2010, 103 (3), pp.457-473. 10.1007/s00015-010-0029-x . insu-00520598

\section{HAL Id: insu-00520598}

https://hal-insu.archives-ouvertes.fr/insu-00520598

Submitted on 7 Jan 2011

HAL is a multi-disciplinary open access archive for the deposit and dissemination of scientific research documents, whether they are published or not. The documents may come from teaching and research institutions in France or abroad, or from public or private research centers.
L'archive ouverte pluridisciplinaire HAL, est destinée au dépôt et à la diffusion de documents scientifiques de niveau recherche, publiés ou non, émanant des établissements d'enseignement et de recherche français ou étrangers, des laboratoires publics ou privés. 
Pétrographie et géochimie comparées des pellets phosphatés et de leur gangue dans le gisement phosphaté de Ras-Draâ (Tunisie). Implications sur la genèse des pellets phosphatés.

Aida Ben Hassen ${ }^{(1)}$, Jean Trichet ${ }^{(2)}$, Jean-Robert Disnar ${ }^{(2)}$, Habib Belayouni ${ }^{(3)}$

(1) Centre de Recherche et des Technologies de l'Energie, Technopôle Borj Cédria, Tunisie aida.benhassen@crten.rnrt.tn

(2) Institut des Sciences de la Terre d'Orléans, Université d'Orléans-CNRS-Université François Rabelais - Tours, Campus Géosciences, 1A rue de la Férollerie, 45071 Orléans.

(3) Université de Tunis El Manar, Faculté des Sciences de Tunis, Département de Géologie, 2092 Tunis, Tunisie

\section{Mots clés : phosphates, pellets, exogangue, conditions oxydo-réductrices, fèces}

\section{Résumé}

Les séries phosphatées tunisiennes, d'âge Paléocène-Eocène inférieur, sont constituées d'alternances de strates richement phosphatées $\left(\mathrm{P}_{2} \mathrm{O}_{5} \geq 18 \%\right)$ et de strates intercalaires peu riches en $\mathrm{P}\left(\mathrm{P}_{2} \mathrm{O}_{5} \leq 2 \%\right)$. Les strates phosphatées sont constituées d'un sédiment argilo-carbonaté servant de matrice (ou exogangue) à des grains phosphatés, arrondis, de taille comprise majoritairement entre 100 et $500 \mu \mathrm{m}$, appelés pellets, et à des grains cylindriques d'origine fécale. L'étude des pellets phosphatés et de leur exogangue dans les strates riches et des sédiments intercalaires peu riches en $\mathrm{P}$ dans le gisement de phosphates de Ras-Draâ (Bassin de Gafsa-Metlaoui, Tunisie ; Fig.1) a réuni des observations microscopiques et diverses analyses chimiques des phases minérales présentes au sein des pellets et des sédiments (matrices et sédiments intercalaires).

Le constituant apatitique majeur des grains est la carbonate-fluorapatite, ou francolite, dont une formule structurale, déterminée sur un échantillon représentatif, est la suivante : $\left.\left(\mathrm{Ca}_{4,63} \mathrm{Mg}_{0,13} \mathrm{Na}_{0,22}\right)\left(\mathrm{PO}_{4}\right)_{2,51}\left(\mathrm{CO}_{3}\right)_{0,48}\right)\left(\mathrm{OH}_{0,77} \mathrm{~F}_{0,23}\right)$. Les constituants des sédiments encaissant ces grains (matrice) et des strates intercalaires sont de nature minéralogique essentiellement argileuse, carbonatée ou siliceuse (opale ou quartz).

Les observations microscopiques et géochimiques de ces différentes phases conduisent à reconnaître que les pellets sont des corps étrangers au sein de leur matrice et de composition tout à fait indépendante de celle de leur exogangue. Les éléments fécaux cylindriques et les pellets arrondis qui en seraient dérivés par fragmentation et érosion, auraient été produits par des 
poissons, sous forme de fèces riches en $\mathrm{P}$ et en matière organique et résistants vis à vis de la dispersion mécanique. Cette dernière propriété a valu à leur contenu de n'être pas dispersé au cours de la sédimentation et des remaniements sédimentaires. Leur contenu a connu, tout au long de leur évolution diagénétique, des conditions réductrices strictes.

Compared petrography and geochemistry of phosphatic pellets and their matrix in the phosphatic deposit of Ras-Draâ (Tunisia). On the genesis of phosphatic pellets.

Key words : phosphates, pellets, exogangue, oxido-reducing conditions, faeces

\section{Abstract}

The Paleocene-Early Eocene phosphate outcrop in the Ras-Draâ deposit (Tunisia; Fig.1) comprises alternances of $\mathrm{P}$-rich strata $\left(\mathrm{P}_{2} \mathrm{O}_{5} \geq 18 \%\right)$ and P-poor ones $\left(\mathrm{P}_{2} \mathrm{O}_{5} \leq 2 \%\right)$. In phosphate rich strata, $\mathrm{P}$ is concentrated in rounded grains - so-called pellets - ( $\left.28 \% \leq \mathrm{P}_{2} \mathrm{O}_{5} \leq 38 \%\right)$ embedded in a matrix - so-called exogangue - much poorer in $\mathrm{P}\left(\mathrm{P}_{2} \mathrm{O}_{5} \# 7 \%\right)$ than pellets. The study of pellets (whose size lies mainly between 100 and $500 \mu \mathrm{m}$ ), of their surrounding matrix and of poorly phosphatic sediments interlayered between the phosphatic strata, has been performed by photonic microscopy and various chemical analyses, ICP-AES (Inductively Coupled Plasma-Atomic Emission Spectroscopy) and punctual chemical analyses by EDS (Energy Dispersive Spectroscopy).

Mineralogical and chemical studies of the Tunisian phosphatic pellets show that the basic mineralogical component of these grains is carbonate-fluor-apatite, or francolite. The structural formula of a representative specimen of francolite in the basin is as follows: $\left(\mathrm{Ca}_{4,63} \mathrm{Mg}_{0,13} \mathrm{Na}_{0,22}\right)\left(\mathrm{PO}_{4}\right)_{2,51}\left(\mathrm{CO}_{3}\right)_{0,48}\left(\mathrm{OH}_{0,77} \mathrm{~F}_{0,23}\right)$. The mineralogy of the constituents of the sediment surrounding pellets comprises carbonates, clays, silica (opal, quartz).

Microscopic observations of Ras-Draâ phosphorites, added to geochemical results, establish that pellets are small bodies, allochtonous to their matrix and whose composition is independent of that of this matrix. Fecal cylindrical bodies and subspherical pellets, the latest being supposed to proceed from the fecal bodies by fragmentation, are considered to have been formed by fishes, as P-rich and organic matter-rich faeces. These faeces turn out to be resistant to mechanical dispersion and to chemical diffusion of soluble elements from and in direction of sea water. This closeness is responsible for the strong reducing conditions having prevailed inside and during the pellets diagenesis. 


\section{ABRIDGED ENGLISH VERSION}

\section{Introduction}

Investigators of Tunisian phosphatic deposits (Cayeux 1896, 1941; Sassi 1974; Belayouni 1983; Belayouni and Trichet 1983; Béji-Sassi 1984; Zaier 1984; Chaâbani 1995; Ben Hassen 2007) faced a characteristic grain-texture, essentially within "fertile", ie P-rich $\left(\mathrm{P}_{2} \mathrm{O}_{5} \geq 18 \%\right)$ phosphatic layers. These authors showed that phosphatic minerals are essentially concentrated in phosphatic grains - called pellets - elongated to sub-spherical, with various sizes (mainly 100 to $500 \mu \mathrm{m}$ ), and colours (from pale yellow to black, under analyzed light). These grains are surrounded by a sedimentary matrix, named exogangue, of brown-yellowish colour and displaying typical low water depth sedimentary structures. The chemical composition of the phosphatic pellets obtained by ICP-AES shows high $\mathrm{P}$ contents in these grains $\left(\mathrm{P}_{2} \mathrm{O}_{5}\right.$ ranging between $28.41 \%$ and $38.31 \%$ ) whereas this content is lower both in the matrix of the pellets (ca. 7\% $\mathrm{P}_{2} \mathrm{O}_{5}$ ) and in the sterile, interlayered, $\mathrm{P}$-poor strata $\left(\mathrm{P}_{2} \mathrm{O}_{5} \leq 2 \%\right)$. The origin of the pellets has been long debated and the

opinions ranged essentially in two directions: either the pellets are considerd as diagenetic authigenic bodies formed within the matrix and still containing mineralogical or chemical elements inherited from the matrix, or the pellets are considered allochtonous bodies (for example faecal pellets), formed outside the matrix and whose composition was consequently not related to that of the matrix. Our study aimed to separate significant amounts of both pellets and matrix phases in order to carry compared studies of their petrography and geochemistry and to draw some pertinent conclusions on the genesis of the pellets in the Ras-Draâ ore.

\section{Material and methods}

The studied samples were collected from the ore of Ras-Draâ (Gafsa-Métlaoui basin, Tunisia; Fig.1). The phosphatic grains were separated from their surrounding exogangue by handprocessing under water. Sieving allowed the separation of grains (size $>50 \mu \mathrm{m}$ ) and matrix (size $<50 \mu \mathrm{m})$. We considered for analysis grains whose size lied between 100 and $500 \mu \mathrm{m}$ and whose proportion is close to $90 \%$, by weight of total grain fraction. The study of both fractions, pellets and matrix, has been performed using photonic microscopy, global chemical analyses by ICPAES (Inductively Coupled Plasma-Atomic Emission Spectroscopy) and punctual chemical analyses by EDS (Energy Dispersive Spectroscopy).

\section{Results}

The main results of the petrographic and geochemical analyses in both fractions are as follows: 
1. Observations under the photonic microscope of the P-rich strata (phospharenites) highlight the "grain-texture" characteristic of these phosphate-rich strata, made up of ovoid grains surrounded by a matricial sediment. The number of pellets within a given rock volume (surface under microscope field) is variable, reaching highest value when pellets are in contact one with several other ones. This pattern of repartition suggests reworking of the pellets (pl. I, photo 4). Under the photonic microscope (pl. I, photos 4-6), the microstructure of pellets appears very variable: some grains don't display any internal structure; others show some rare concentric peripheral envelops. Many of the pellets are bordered by a thin $(<5 \mu \mathrm{m})$, clear, external envelop. This envelop bears frequently the printed mark of smaller adjacent pellets (pl. I, photos 1-3), suggesting that the external part of the larger pellets was smooth when smaller ones came in contact with them, during reworking.

2. X-ray diffraction spectra of pellets are typical of carbonate-fluorapatite (CFA), also called francolite, being an apatite substituted for anions $\left(\mathrm{PO}_{4}{ }^{3-}\right)$ and for cations $\left(\mathrm{Ca}^{2+}\right)$. The formula of a representative sample of apatite within a selected pellet in the Ras-Draâ- was $\left(\mathrm{Ca}_{4,63} \mathrm{Mg}_{0,13} \mathrm{Na}_{0,22}\right)\left(\mathrm{PO}_{4}\right)_{2,51}\left(\mathrm{CO}_{3}\right)_{0,48}\left(\mathrm{OH}_{0,77} \mathrm{~F}_{0,23}\right)$.

\section{Conclusion}

The purpose of this work was to bring some light on the nature of petrographical, mineralogical and geochemical similarities or differences existing between phosphatic pellets and their surrounding matrix, as well as between pellets, their matrix and the sterile $\mathrm{i}$ sediments interlayerd between P-rich strata.

The detailed examination of the chemical composition of the two main fractions of the same phosphatic layer (pellets and matrix), shows basic differences between those fractions. The reasons of this specificity must been sought in the origin and the diagenetic history of the grains and of the matrix. The organic matter present in the pellets and in the matrix witnesses very clearly different diagenetic processes undergone in each fraction. The more significant pattern of diagenesis is that provided by the organic matter present within pellets, which underwent diagenesis under strictly closed and reducing conditions, leading to humic compounds while the organic fraction of the matrix evolved under more open, oxidizing conditions, leading to a kerogen-like constituent. The close similarity between cylindrical faecal bodies and the subspherical pellets suggests that the second proceeded from the first ones by fragmentation. Both have been produced by carnivorous fishes, as P-rich (due to non digested fish bones and scales) 
and organic matter-rich faeces. The faecal bodies are remarkable through the resistance of their envelop towards rupture and through their weak permeability to external as well as internal fluids. This property explains also that the diagenetic conditions underwent by constituents inside the pellets were definitely reducing. 


\section{Introduction}

Les premiers travaux portant sur la sédimentologie des dépôts phosphatés tunisiens (Cayeux 1896, 1936, 1941; Sassi 1974; Visse 1974) y ont reconnu l'alternance de strates riches en $\mathrm{P}_{(}\left(\mathrm{P}_{2} \mathrm{O}_{5}\right.$ $\geq 18 \%$ ), dites "fertiles" et de strates pauvres en $\mathrm{P}\left(\mathrm{P}_{2} \mathrm{O}_{5} \leq 2 \%\right)$, dites "stériles" (Fig. 2). La structure typique des strates fertiles est celle de "phosphates en grains" où la minéralisation phosphatée est essentiellement concentrée dans des grains phosphatés $\left(28 \% \leq \mathrm{P}_{2} \mathrm{O}_{5} \leq 38 \%\right)$ ou "pellets", entourés par une matrice ou exogangue $\left(\mathrm{P}_{2} \mathrm{O}_{5} \# 7 \%\right)$. Ces pellets ont une forme allongée à sub-sphérique (pl. I, photo 1) et leur taille varie entre 50 et $800 \mu \mathrm{m}$, avec un mode marqué entre 100 et $500 \mu \mathrm{m}$.

Dès les premiers travaux cités ci-dessus, l'origine de ces pellets a été débattue et a conduit au constat suivant: parmi les grains phosphatés trouvés dans les gisements certains étaient des bioclastes phosphatisés (débris d'os, de coquilles, d'échinodermes). D'autres contenaient, sous forme de nucleus, des grains de quartz de la taille des sables. Ces grains avaient, à l'évidence, une double origine, pour une part détritique (éléments osseux, sables quartzeux) et, pour une autre part, chimique ou biochimique (phosphate enrobant les éléments détritiques). Le problème en discussion provenait, en vérité, du cas de la très grande majorité des grains (pellets) phosphatés qui ne présentent pas de caractère apparent d'une genèse polyphasée. La précipitation du phosphate étant un processus fréquent au sein des sédiments (Bréhéret 1991), celle du phosphate associé aux pellets a été considérée comme un processus essentiellement autochtone et authigénique (Cayeux 1896; Riggs 1979; Soudry et Nathan 1980; Krom et Berner 1981; Lamboy 1982; Benmore et al. 1983; Soudry et Champetier 1983; Baker et Burnett 1988; Froelich et al. 1988; Glenn et Arthur 1988; Garrison et Kastner 1990; Glenn 1990; Lewy 1990; Ece 1990; Gächter et Meyer 1993; Soudry 1993; Ruttenberg et Berner 1993; Föllmi 1996; Louchouarn et al. 1997; Jarvis 2006). Mais si la précipitation authigénique de ciments phosphatés au sein de sédiments est ainsi bien reconnue, la formation diagénétique de grains possédant une morphologie reproductible -concrétions, nodules et, surtout, pellets, phosphatés - a donné lieu à discussion. L'un des arguments plaidant en faveur de l'authigenèse de ces grains était la présence, au sein de ceux-ci, de restes identifiables de constituants de leur matrice, par exemple de filaments plus ou moins désorganisés de cyanobactéries (Riggs 1979; Soudry et Nathan 1980; Lamboy 1982; Soudry et Champetier 1983; Lamboy 1987, a, b; Lewy 1990; Soudry 1993). Mais certaines observations viennent plaider en faveur d'une origine véritablement allochtone des es 
éléments appelés à constituer les pellets de certains dépôts phosphatés. Tel est le cas du gisement tunisien de Ras-Draâ faisant l'objet de la présente contribution.

Il convenait, pour confirmer, ou infirmer, une parenté sédimentaire entre les pellets et leur matrice de séparer ces deux phases afin de les soumettre à des analyses comparatives. Cette démarche est habituelle en pétrologie sédimentaire où se côtoient, dans les mêmes sédiments ou les mêmes roches, des éléments d'origine, de nature et d'âge potentiellement différents. S'ajoute à la nécessité de cette démarche le fait que la majorité des études géochimiques sur des dépôts phosphatés tunisiens, ont porté jusqu'à présent sur des roches phosphatées globales. Analyser séparément des pellets et leur matrice avait donc une portée nouvelle.

\section{Matériel et méthodes}

\subsection{Contexte géologique}

Le site retenu pour ce travail est le gisement de phosphate de la région de Ras-Draâ, situé entre Tozeur et Nefta, en Tunisie méridionale. Ce gisement fait partie du grand bassin phosphaté de Gafsa-Métlaoui (Fig.1). Les dépôts phosphatés de ce gisement sont organisés en 10 couches phosphatées "fertiles" (économiquement exploitables; $\mathrm{P}_{2} \mathrm{O}_{5} \geq 18 \%$ ), séparées par des couches "stériles" (à faibles teneurs en phosphate ; $\mathrm{P}_{2} \mathrm{O}_{5} \# 3 \%$ ) (Fig.2).

\subsection{Séparation des pellets phosphatés et de leur exogangue}

L'échantillon de roche brute est d'abord débourbé en milieu aqueux, puis introduit dans une allonge où le volume sédiment + eau est complété à $1000 \mathrm{ml}$. Après homogénéisation du contenu de l'éprouvette par agitation, les grains phosphatés sont récupérés par décantation. La fraction fine $(<50 \mu \mathrm{m})$ restée en suspension est récupérée par centrifugation. Les fractions de taille supérieure (culot de sédimentation) sont séparées par tamisage sur une colonne de tamis (norme AFNOR) de mailles progressivement décroissantes, de $2 \mathrm{~mm}$ à $50 \mu \mathrm{m}$. Les différentes fractions récupérées sont ensuite séchées à l'étuve à $40{ }^{\circ} \mathrm{C}$, pesées et conservées dans des bocaux en verre.

\subsection{Méthodes microscopiques d'observation et d'analyses chimiques}

Des échantillons bruts de matériaux présentant divers faciès et des lames minces ont été respectivement étudiés à l'aide d'un stéréo-microscope de type Zeiss STEMI SV 11 et d'un microscope photonique de type Leica DMR XP en lumière naturelle.

L'analyse des éléments majeurs ( $\mathrm{P}, \mathrm{Si}, \mathrm{Al}, \mathrm{Fe}, \mathrm{Mg}, \mathrm{Mn}, \mathrm{Ca}, \mathrm{Na}, \mathrm{K}$ ) dans les pellets phosphatés et dans leurs exogangues, a été réalisée par spectrométrie d'émission Plasma à Couplage Inductif "ICP-AES" (Inductively Coupled Plasma-Atomic Emission Spectroscopy) à l'aide d'un 
spectromètre de type Jobin-Yvon ULTIMA à visée radiale. Les échantillons ont été préalablement mis en solution par fusion alcaline, dans un creuset en graphite à l'aide d'une perleuse, après l'ajout d'un fondant $\left(\mathrm{LiBO}_{2}\right)$. Des analyses chimiques ponctuelles ont été effectuées avec une microsonde électronique de type CAMECA SX 50 sur des échantillons préparés sous forme de sections polies de $25 \mathrm{~mm}$ de diamètre.

\section{Résultats et discussion}

\subsection{Caractérisation granulométrique}

Dans les strates phosphatées, l'analyse granulométrique a révélé une prédominance marquée, atteignant environ $90 \%$ en poids, de particules de taille comprise entre 100 et $500 \mu \mathrm{m}$. Ces particules sont essentiellement des pellets. C'est à cette fraction qu'a été appliqué l'ensemble de notre étude. Le complément de cette fraction est formé par des éléments du sédiment encaissant (de taille $<100 \mu \mathrm{m}$ ) et des allochèmes (de taille $>500 \mu \mathrm{m}$ ) tels que des lithoclastes et des bioclastes, notamment des dents de poissons. Les fractions fines $(<50 \mu \mathrm{m})$ appartenant respectivement aux strates phosphatées et aux niveaux stériles sont désignées, dans la suite de cet article, sous les noms de "matrices" et d'"intercalaires".

\subsection{Caractérisations pétrographiques des pellets phosphatés et de leurs matrices}

Sous la loupe la fraction des pellets isolés $(100-500 \mu \mathrm{m})$ (Planche 1, photos 1, 2, 3), montre une certaine hétérogénéité dans les formes et dans les teintes des différents grains. Les pellets ont des formes allant de celles de cylindres (Planche 1, photo 2) à celles de sphères plus ou moins parfaites, ainsi que de nombreuses formes intermédiaires (Planche 1, photos 1 et 3). Les pellets sont très souvent juxtaposés (Planche 1 , photos 4,5 et 6 ) et constituent des assemblages quasicompacts, témoignant soit d'une néogenèse "rapprochée" au sein de la matrice, si ces pellets procèdent d'une authigenèse au sein du sédiment, soit d'un arrangement mécanique en mode "compact" au cours de remaniements sédimentaires, si les pellets préexistaient par rapport à ces remaniements. Leur couleur extérieure se rattache à deux teintes principales, le blanc-gris et le brun (Planche 1, photos 1, 2 et 3). De nombreux pellets blancs-gris révèlent que cette couleur extérieure est en fait celle d'une mince pellicule $(<5 \mu \mathrm{m}$. Planche 1 , photos 4,6$)$ dont l'origine sera discutée plus loin. De nombreux pellets de couleur claire portent des marques d'impression laissées par d'autres pellets, généralement plus petits qu'eux (Planche 1, photos 1 et 3). Ces petits pellets sont d'ailleurs, assez fréquemment, retrouvés fixés sur le pellet-support. Une telle disposition témoigne de la présence, au sein du sédiment, de pellets, gros et plus petits. Elle 
témoigne aussi du fait que la pellicule claire qui les entourait, les uns et les autres, (Planche 1, photo 2) était molle, avant de se charger d'apatite, par la suite. Cette pellicule sera ultérieurement érodée ou dissoute dans la plupart des pellets matures, laissant apparaître la couleur brune fondamentale de leurs constituants internes (Planche 1, photos 1 et 2). Celle-ci apparaît d'ailleurs, au fond des sites de fixation des petits pellets sur les plus gros (Planche 1, photo 3).

Au microscope photonique, la microstructure des pellets apparaît variable. La majeure partie des grains ne montre aucune structure interne particulière (Planche 1, photos 4-6). Le matériau se présente comme un assemblage complexe d'éléments jaunâtres, brunâtres et noirâtres, en lumière naturelle. Les éléments sombres occupent la quasi totalité des pellets. Ils sont constitués de petites particules elles-mêmes sombres, d'environ $10 \mu \mathrm{m}$ de dimension moyenne (Planche 1, photos 5 et 6). Les parties plus externes du pellet, parfois lamellaires, présentent des couleurs d'un brun plus léger à jaune.

Comme cela a été maintes fois signalé (Cayeux 1896, 1936, 1941), certains pellets peuvent contenir des nucléus (os de poissons, dents...) ou des microfossiles (dinoflagellés, radiolaires) (Planche 1, photos 4 et 6).

L'exoguangue des pellets a, quant à elle, les propriétés d'un sédiment détritique fin à moyen, souvent remanié. Ce sédiment est de nature argileuse, carbonatée, argilo-carbonatée ou siliceuse, parfois phosphatée. Les matrices carbonatées et argileuses (marnes) sont les plus abondantes dans les phosphorites yprésiennes du gisement de Ras-Draâ. Les matrices dolomitiques sont aussi fréquentes, montrant, par endroit, un développement spectaculaire de rhomboèdres de dolomite automorphe à cœur sombre, témoignant du fait que les conditions physiques et chimiques dans lesquelles a eu lieu la dolomitisation ont été celles - ou voisines de celles - dans lesquelles ont évolué les pellets phosphatés au cours de leur enfouissement précoce.

L'exogangue est également plus ou moins pigmentée par de la MO (Planche 1, photos 5 et 6). La présence de MO planctonique dans la matrice résulte d'apports de MO d'origine marine (dinoflagellés, foraminifères), ou, comme nous l'avons observé dans des lames minces, d'un de matière organique héritée de pellets, fragiles, et dont le contenu a été dispersé au sein de la matrice.

\subsection{Caractérisation chimique des pellets phosphatés et de leurs matrices}

Les résultats de l'analyse chimique globale des pellets phosphatés, de leurs matrices et des sédiments intercalaires, reportés dans le tableau 1, reflètent la composition minéralogique de ces 
fractions dans les strates phosphatées et non phosphatées. Les pellets sont constitués d'apatite carbonatée alors que la matrice et les intercalaires ont des compositions minéralogiques variées, essentiellement argileuses, carbonatées et siliceuses. Les résultats obtenus conduisent aux constats suivants : (i) les teneurs en $\mathrm{P}_{2} \mathrm{O}_{5}$ sont élevées dans les pellets $\left(28,41 \%<\mathrm{P}_{2} \mathrm{O}_{5}<38,31 \%\right)$, moyennes dans les matrices $\left(2,70 \%<\mathrm{P}_{2} \mathrm{O}_{5}<12,49 \%\right)$ et faibles dans les intercalaires $(0,83 \% \leq$ $\mathrm{P}_{2} \mathrm{O}_{5} \leq 2,00 \%$ ), à l'exception de l'échantillon INT I-II qui affiche une valeur de 14,52\%. Les valeurs du rapport $\mathrm{CaO} / \mathrm{P}_{2} \mathrm{O}_{5}$, voisines de 1,90 dans les pellets phosphatés $(1,31$ pour la fluorapatite), reflètent l'existence de substitutions isomorphiques d'ions phosphates par des ions $\mathrm{CO}_{3}{ }^{2-}$ dans le réseau cristallin de l'apatite (Guldbrandsen 1966) ; (ii) les teneurs en $\mathrm{SiO}_{2}$ dans les pellets, bien que faibles $(2,55 \%$, en moyenne, $n=8)$, en comparaison de celles observées dans les matrices $(32,87 \%)$ et les intercalaires $(38,95 \%)$, témoignent de la présence de silice dans l'endogangue des pellets phosphatés. Nous interprétons cette présence de silice comme le résultat de l'incorporation de tests de radiolaires ou d'algues siliceuses dans les pellets ou encore comme le résultat de la présence de silice dissoute dans la solution interstitielle de ces grains au moment de leur formation. Les pourcentages élevés de $\mathrm{SiO}_{2}$ dans les matrices et les intercalaires reflètent la présence d'argiles (smectite, attapulgite, sépliolite, kaolinite, glauconite, illite ; Sassi 1974). Il en est de même de ceux des éléments majeurs $\mathrm{Al}, \mathrm{Fe}, \mathrm{Mg}, \mathrm{K}$.

L'analyse ponctuelle, à la microsonde électronique, a déjà été utilisée pour localiser tel ou tel élément chimique dans les paragenèses compliquées des roches phosphatées (Champetier 1976; Baioumy et al. 2007).

Les résultats des analyses réalisées par cette méthode dans les phosphates de Ras-Draâ sur six éléments majeurs représentatifs des paragenèses phosphatées $(\mathrm{P}, \mathrm{Ca}, \mathrm{Si}, \mathrm{Mg}, \mathrm{F}, \mathrm{S})$ sont illustrés dans la figure 3. Cette figure permet de confronter visuellement, les quantités d'un même élément dans des pellets, dans leur matrice et dans certains sédiments intercalaires. Elle montre :

1. que les teneurs en phosphore, en calcium et en fluor varient dans le même sens, avec de fortes concentrations au sein des grains phosphatés par rapport à leur matrice. La distribution de ces éléments est assez homogène au sein des grains, et ne montre, à cette échelle, aucune concentration préférentielle. La répartition du phosphore dans les grains phosphatés n'y montre, en particulier, pas de zonation ou de concentration différentielle. Seule peut être observée, autour de certains pellets, la présence d'une enveloppe fine où la concentration en phosphore et en 
calcium est plus faible mais plus élevée en silicium, en magnésium et en soufre qu'au sein du grain. Il s'agit de la pellicule blanchâtre évoquée plus haut.

2. que la silice est la plus concentrée dans la matrice intergranulaire. Sa concentration (exprimée en $\mathrm{Si}$ ) peut y atteindre $200 \mu \mathrm{g} / \mathrm{g}$. A l'inverse, les teneurs moyennes en silicium au sein des grains sont comprises entre 40 et $80 \mu \mathrm{g} / \mathrm{g}$.

3. Le magnésium est réparti entre les grains - où l'on sait qu'il entre dans la composition de la francolite - et la matrice où il entre dans la composition d'argiles magnésiennes ainsi que dans celle de la dolomite.

La combinaison de ces résultats avec ceux de l'analyse minéralogique par DRX des pellets et de leur exogangue confirme que le constituant apatitique typique des pellets (et de leurs matrices) est la carbonate fluor-apatite ou francolite (Ben Hassen 2003). La francolite de ce gisement est caractérisée par la faiblesse des valeurs des paramètres de maille a et $\mathrm{c}$ : variant respetivement entre 9,291 et $9,322 \AA$, et 6,874 et $6,899 \AA$, ce qui indique l'existence de substitutions isomorphiques significatives dans cette famille minéralogique de la carbonate-fluor-apatite (Bonel et al. 1973). La formule structurale d'une apatite purifiée extraite de pellets du gisement de Ras-Draâ est la suivante : $\left(\mathrm{Ca}_{4,63} \mathrm{Mg}_{0,13} \mathrm{Na}_{0,22}\right)\left(\mathrm{PO}_{4}\right)_{2,51}\left(\mathrm{CO}_{3}\right)_{0,48}\left(\mathrm{OH}_{0,77} \mathrm{~F}_{0,23}\right)$.

\section{Discussion générale}

En prenant pour objet d'étude la série phosphatée du gisement de Ras-Draâ, nous avons cherché à révéler les différences ou les similitudes de nature pétrographique, minéralogique ou géochimique existant entre les trois fractions lithologiques constitutives des sédiments de la série phosphatée yprésienne du Sud-tunisien. Ces fractions sont celles des pellets phosphatés, de leur matrice et des sédiments peu riches en P intercalaires entre les couches phosphatées "fertiles". A notre connaissance, ces trois types de fractions n'ont pas fait l'objet d'études pétrographiques, minéralogiques et géochimiques comparées et systématiques. Par contre de nombreuses analyses ont porté sur des échantillons globaux de phosphorites du bassin de Gafsa-Métlaoui (Sassi 1974; Slansky 1980; Béji-Sassi 1984; Chaâbani 1995).

\subsection{Comparaison entre la composition pétrographique, minéralogique et chimique des pellets et de leur matrice}

Sous tous ces angles, la composition des pellets et de leur matrice diffère radicalement (1) purement apatitique dans les pellets, la composition minéralogique des matrices se partage entre des phases argileuses, carbonatées et siliceuses. Lorsque de l'apatite est présente dans la matrice, 
elle y est héritée de celle de pellets dont le contenu y a été dispersé mécaniquement (2) la pétrographie des pellets montre une association binaire entre de l'apatite et de la matière organique. Au sein de la matrice elle est typique de celle de sédiments marins de faible profondeur, fins à moyens, remaniés (3) la composition géochimique des deux phases est fondamentalement différente. Les analyses des éléments minéraux, à la microsonde, montrent des répartitions bien différentes dans les deux phases: résumer cette affirmation en quelques mots. Mais c'est surtout la géochimie de la matière organique qui oppose ces deux phases : celle-ci est, tout d'abord, moins abondante dans les pellets $(0,3 \%<$ Corg. $<1,62 \%$ du poids des pellets $)$ que dans les matrices $(1,22 \%<$ Corg. $<4,00 \%)$ (Ben Hassen et al. 2009). Mais elle est surtout présente sous forme humique dans les pellets et sous forme d'un kérogène immature dans les matrices. Les composés humiques se sont constitués dans un milieu anoxique, au sein des pellets, le kérogène des matrices dans un milieu suboxique (Belayouni et Trichet 1983; Ben Hassen 2007).

Tout distingue donc les pellets de leurs matrices (et des sédiments intercalaires, très semblables aux matrices) et aucun trait, minéralogique, pétrographique ou géochimique, ne plaide, dans le gisement de Ras-Draâ, en faveur d'une genèse des pellets par des mécanismes diagénétiques authigènes au dépens du sédiment initial représenté par la matrice.

\subsection{Enseignements recueillis sur l'origine des pellets}

A travers ces analyses, nous avons cherché à apporter des éléments à même d'éclairer le débat sur le caractère autochtone ou allochtone de la genèse des pellets. Deux données fournies par l'observation des pellets, sous la loupe binoculaire éclairent ce problème

\section{- $\quad$ Informations données sur l'origine des pellets par leur morphologie}

La première de ces données est la continuité dans la morphologie existant entre les pellets subsphériques ou sphériques et les éléments cylindriques, plus ou moins émoussés et de taille voisine de celle des pellets (Planche 1, photos 1, 2 et 3). Ces éléments cylindriques sont unanimement reconnus comme des éléments fécaux. Les organismes qui les ont engendrés ne sont pas connus avec précision mais leur taille et leur abondance incitent à penser qu'il s'est agi de poissons de 20 à $25 \mathrm{~cm}$ et de 0.3 à $0.5 \mathrm{~kg}$, environ (communication personnelle de M. Dominique Bureau, Laboratoire "Fish Nutrition Research", Université de Guelph, Canada).

La continuité ayant existé entre ces éléments fécaux et les pellets implique plusieurs conclusions sur le comportement de ceux-ci au cours de leur sédimentation, de leurs remaniements et de leur 
dépôt. Leur forme émoussée suppose que les éléments fécaux ont été remaniés et usés. La répartition irrégulière des pellets au sein des strates fertiles et leur regroupement fréquent en "assemblages compacts" sont des témoignages de ces remaniements. Ces derniers n'ont pas entraîné la dispersion du contenu des pellets, au cours de leur transit dans l'eau de mer ou de leurs remaniements sédimentaires. La localisation quasiment exclusive du $\mathrm{P}$ au sein des pellets témoigne d'un tel comportement, nuancé cependant par les deux variantes suivantes. Il n'est pas rare, en effet, d'observer, en lame mince, des pellets "ouverts", déchirés, et dont le contenu a commencé à se disperser dans la matrice ou dans les strates intercalaires (où de rares pellets peuvent avoir été incorporés à la suite de remaniements ; Planche 1, photo 6). Ce processus est à l'origine de l'enrichissement en $\mathrm{P}_{2} \mathrm{O}_{5}$ de la matrice (ca. $7 \%$ ) et des strates intercalaires $\left(\mathrm{P}_{2} \mathrm{O}_{5} \leq 2\right.$ $\%)$. La deuxième variante à la répartition fondamentale du $\mathrm{P}$ dans les pellets tient au fait que la teneur en $\mathrm{P}$ dans la matrice est la plus élevée à la périphérie des pellets (Fig. 3), suggérant qu'une certaine diffusion de cet élément peut intervenir au profit de la matrice, tardivement, aux dépens des pellets. Mais ces deux faits ne remettent pas en cause - et ne font que souligner, par leur caractère accessoire - la stabilité des pellets jusqu'à leur enfouissement final.

La place occupée par des déjections fécales de poissons dans la genèse des gisements de phosphate a été très tôt reconnue. Elle s'est vite imposée par l'observation de la présence systématique, dans les strates phosphatées, de pelotes fécales ou de coprolites d'une taille conforme à celle de fèces de poissons ou de crustacés, aux côtés de restes de dents ou d'écailles également typiques de ce poissons. Certains auteurs ont insisté sur l'importance quantitative de ces éléments fécaux au sein des constituants biogènes des sédiments (Martinez 2003). Mais l'on doit à Lamboy d'avoir affirmé que les éléments fécaux pouvaient avoir une part essentielle dans la constitution de gisements phosphatés (Lamboy 1982; Lamboy et al. 1994). Lamboy se référait, dans cette affirmation, à des gisements tunisiens. Nous nous rangeons à cette conclusion, à l'issue de l'étude du gisement de Ras-Draâ.

\section{Informations données sur l'origine des pellets par leur couleur}

L'image de pellets susceptibles de subir une certaine érosion au cours de remaniements tout en étant protégés contre la dispersion de leur contenu se confirme grâce aux enseignements fournis à nouveau par l'observation des pellets à la loupe binoculaire. Cette observation concerne la couleur des éléments précocement excrétés (éléments fécaux cylindriques, essentiellement) et de quelques rares pellets, dérivés des premiers. Les formes cylindriques ou sub-cylindriques sont 
majoritairement claires (Planche 1, photo 2), à l'inverse des formes arrondies qui sont brunes. L'explication de cette différence est aisément fournie par l'observation microscopique. Les éléments clairs sont, en effet, entourés d'une mince pellicule $(<5 \mu \mathrm{m})$, apatitique, rares ou absente dans les pellets arrondis (Planche 1, photos 1 et 3). Sans exclure, a priori, que cette pellicule ait pû se former diagénétiquement autour des éléments cylindriques ou sub-arrondis, une explication biologique de son origine et de sa régularité autour des grains est beaucoup plus convaincante.

Il a été, en effet, reconnu que les invertébrés marins et en particulier les crustacés planctoniques enrobent leurs éléments fécaux, avant même de les excréter, d'une pellicule dite "membrane péritrophique" (Lautenschlager et al. 1978; González et Biddanda 1990). De telles membranes, ont également été observées chez certains poissons (les tilapias par exemple, Bowen 1981), où elles protégent la paroi digestive contre l'effet abrasif de certaines particules alimentaires (Wotton and Malmqvist 2001). Ces auteurs ont signalé également que la présence de mucus dans les fèces de vertébrés et de la majorité des invertébrés, favorise, en l'absence de membrane externe, la cohésion de ces particules et leur stabilité de plusieurs jours à plusieurs semaines. Par conséquent, la présence d'une enveloppe protectrice "péritrophique" (chez les invertébrés et certains poissons) ou de mucus agglutinant (chez certains vertébrés et invertébrés), assure un transit rapide de ces éléments fécaux dans l'eau de mer, évitant la dispersion due contenu de ces éléments (Ben Hassen 2007).

En résumé, les propriétés d'une telle pellicule d'origine biologique éclairent ce qui est observé dans les grains fossiles du gisement tunisien: stabilité pendant le transit et au cours des remaniements sédimentaires, malgré leur caractère encore mou. Des pellets de ce type sont donc allochtones par rapport au sédiment encaissant.

La présence de cette pellicule à l'extérieur des pellets sédimentaires avait déjà été signalée par plusieurs auteurs : pellicule phosphatée (Giresse 1980; Slansky 1980) ou calcitique (Baker et Burnett 1988). Mais aucune explication n'avait été donnée par ces auteurs quant à son origine et sa signification.

- $\quad$ La place et le rôle des poissons au début de la formation des grains phosphatés

La richesse en $\mathrm{P}$ du contenu des pellets suppose que ces poissons aient été carnivores, essentiellement piscivores (Lamboy et al. 1994). Le P fossilisé au sein des pellets serait le complément de celui que les poissons auraient assimilé aux dépens du $\mathrm{P}$ de leurs proies 
(squelette, écailles, P biochimique). Ces poissons excrètent, en effet, des quantités significatives de $\mathrm{P}$, soit à cause de la lenteur de leur digestion (D. Bureau, comm. pers.), soit à cause de l'excès de $\mathrm{P}$ disponible (Hua et Bureau 2006). Le rejet du P par les poissons carnivores (piscivores) est une modalité particulièrement intéressante du point de vue de la géochimie sédimentaire car, autant les poissons assimilent rapidement des phosphates minéraux ajoutés, expérimentalement, en poudre à leur alimentation (phosphates de $\mathrm{Na}, \mathrm{K}, \mathrm{Ca}, \mathrm{Mg}$ ) autant ils assimilent beaucoup moins rapidement le phosphate du squelette (vertèbres, arêtes), des écailles et des opercules de leurs proies. Ces éléments figurés subissent un début de dissolution au contact des sucs gastriques - à pH 4-6 - mais celle-ci est inhibée dès l'entrée du bol alimentaire dans l'intestin où le pH atteint rapidement des valeurs voisines de 7-8. A ces $\mathrm{pH}$ les phosphates en solution commencent à précipiter (Hua et Bureau 2006). Ainsi les fèces possèdent-elles, au moment même de leur égestion, une cohérence mécanique (membrane péritrophique) et chimique (précipitation de l'apatite) empêchant leur dispersion dès leur libération et au cours de leur chute dans la colonne d'eau jusqu'à la surface du sédiment. De nombreux essais ont été entrepris afin de renforcer la stabilité des fèces par l'addition de liants (sels, polysaccharides, argiles, silice,...), dans le but de limiter la dispersion du phosphore qu'elles contiennent dans les eaux, les effluents ou les sols (Storebakken 1985; Storebakken et Austreng 1987; Brinker et al. 2005).

Dans les bassins sédimentaires marins, les fèces et les pellets qui en dérivent sont fermes mais encore meubles à leur arrivée à la surface du sédiment et dans les sédiments superficiels. Les pellets sont alors soumis à des pressions mutuelles à même d'entraîner une certaine expulsion de phosphate en solution. Ce phosphate précipite en priorité à la périphérie des grains puis dans leur environnement proche, au sein de leur matrice, sous forme d'encroûtements. Les pressions intergranulaires, entre des pellets adjacents, laissent leur marque à la périphérie des pellets comprimés, essentiellement au sein de la pellicule externe qui les entoure (Fig.3, photos 1-3).

\section{- $\quad$ Données sur la stabilisation des fèces}

Cette conservation du P au sein des pellets n'a d'avenir au sein des sédiments que si les pellets offrent, dès le stade de l'égestion, une stabilité suffisante vis-à-vis des agents dynamiques du milieu (vagues, courants). La précipitation précoce, intra-intestinale, d'apatite est la cause essentielle aux cotés de la très faible porosité des pellets (Ben Hassen 2007). Le volume des grains phosphatés est, en effet, quasi-totalement occupé par des amas apatitiques et par des restes organiques (Ben Hassen 2007). L'occupation quasi-totale du pellet par les minéraux apatitiques 
se comprend eu égard à la concentration en phosphate très élevée au sein du fluide intestinal. La stabilité des pellets est en outre suggérée par la manière "vive" avec laquelle les particules de MO humifiées se dispersent lorsque les minéraux apatitiques sont détruits par l'ajout d'acide, au laboratoire. Ces particules semblent "sous pression" et les composés humiques semblent se disperser sous l'effet d'une véritable détente, Celle-ci reflète la densité et la forte stabilité structurale de ces particules closes. Le pellet apparaît ainsi comme une particule à même d'avoir un destin sédimentaire et géologique. C'est un témoin paléontologique direct de la faune ichtyologique et des biomasses marines (plancton, nekton) de l'époque. Sa fermeture au sein des milieux qui l'ont entouré (eau de mer, sédiment) en a fait le dépositaire d'objets micropaléontologiques (microfossiles, particules digestives) et géochimiques (biomarqueurs organiques, fractions minérales ou organiques au contenu isotopique spécifique - $\mathrm{C}, \mathrm{O}, \mathrm{N}, \mathrm{P}$ ).

\section{- $\quad$ Données sédimentologiques sur l'origine allochtone des pellets}

Sur le plan sédimentologique, l'origine allochtone des grains phosphatés est illustrée par le faciès de dépôt des constituants de ces strates phosphatées: il s'agit de phosphates allochtones (ou "fossil" phosphates ou encore phosphates recyclés) (Föllmi 1996). L'allochtonie et les remaniements de ces constituants peuvent être reconnus aux critères suivants : (i) la présence d'un mélange de particules phosphatées (pellets, coprolites) et de particules non phosphatées (bioclastes, lithoclastes, glauconies, ...); ce mélange irrégulier d'éléments phosphatés et non phosphatés est une propriété fondamentale de la pétrographie des couches phosphatées de la série de Ras-Draâ; (ii) la co-existence de plusieurs générations de particules phosphatées dans la même unité microstratigraphique témoigne de l'effet de multiples évènements de remaniement (Föllmi 1996); (iii) la présence de restes biologiques (dents, vertèbres, épines, écailles, opercules) souvent abrasés confirme ce remaniement lors de transports.

Par ailleurs, de nombreuses observations minutieuses de terrain plaident en faveur de l'origine allochtone des grains phosphatés dans le bassin de Gafsa-Métlaoui. Il est, en effet, fréquent d'identifier la présence au niveau des surfaces supérieures irrégulières des couches phosphatées, de cavités remplies de grains phosphatés rassemblés. De même, dans certains niveaux phosphatés bioturbés tel que la couche I phosphatée, on constate le remplissage des pores engendrés par les bioturbations par des grains phosphatés (travaux en cours de Mlle Ajermi).

Quant aux agents de remaniement, certaines figures sédimentaires reconnues dans les séries phosphatées du bassin de Gafsa-Métlaoui, indiquent un remaniement par le vent (tempestites) 
plutôt qu'un remaniement gravitaire en présence de fluides (débris-flow, turbidites).En témoignent les les indices suivants:(i) le caractère amalgamé ????? Ä̈da? des dépôts phosphatés ; (ii) la présence de nombreuses stratifications obliques entrecroisées à petite échelle ; (iii) le classement granulométrique du sédiment global, généralement assez mauvais ou même l' absence de tout granoclassement; conduisent à penser que les éléments phosphatés ont généralement subi des transports sous l'influence de transports engendrés par des vents (tempestites).

L'histoire de la mise en place d'une série phosphatée n'est donc pas terminée avec la genèse des pellets phosphatés. Ces particules phosphatées individuelles sont transportées, plus ou moins loin, pendant des périodes de haute énergie. La concentration finale des pellets est réalisée par vannage au cours de ces remaniements et détermine la teneur finale de la strate phosphatée en $\mathrm{P}_{2} \mathrm{O}_{5}$.

\subsection{De la nature des fractions organiques et des populations microbiennes au sein des pellets}

La couleur sombre des pellets arrondis recèle des informations sur leur origine. Observée en lame mince (Planche 1, photos 4 et 6), la teinte des pellets procède, schématiquement, de celle de deux composants : des plages jaunâtres, transparentes, correspondant à de l'apatite teintée de composés organiques dilués, et des plages noirâtres dispersées de façon désordonnée au sein des pellets. Il convient de rappeler que l'on doit également à Lamboy (1986) d'avoir montré que beaucoup de plages sombres observées dans des lames minces de roches ne correspondent à aucun élément figuré (particules organiques, minéraux mal cristallisés ou opaques) mais à des pores au sein desquels la lumière traversant la préparation peut se trouver occluse et donner l'impression que le volume correspondant est occupé par un constituant opaque. Une telle situation est souvent rencontrée dans les pellets phosphatés qui possèdent des pores aisément reconnaissables en microscopie électronique (MEB ; Lamboy 1982, 1990; Soudry 1993; Ben Hassen 2007). Mais de nombreuses particules noires au sein des pellets sont bien organiques (les pellets contiennent de 0.30 à $1.62 \%$ de carbone organique total). Leur nature est connue depuis 1982-1983 (Sandstrom 1982; Belayouni et Trichet 1983), années où a été mise en évidence leur nature humique. Il s'agit d'un humus marin, d'origine phytoplanctonique. Si ce résultat a apporté la réponse à la question posée sur la nature des particules sombres au sein des pellets, elle soulève celle, beaucoup plus difficile, de la raison de la stabilité, pendant des durées de l'ordre de $50 \mathrm{Ma}$ (Yprésien), de ces constituants humiques, réputés fragiles. Un élément de réponse à cette 
question est fourni par la confrontation de la nature de la matière organique des pellets avec celle des matières organiques de leur matrice et des sédiments intercalaires. Les deux dernières sont des kérogènes, immatures, d'origine phytoplanctonique, typiques de séries sédimentaires n'ayant jamais été enfouies au delà de $200 \mathrm{~m}$. C'est là une composition habituelle dans ce type de séries marines peu profondes. La singularité se trouve donc bien au sein des pellets où des composés humiques apparaissent avoir été fossilisés au sein de ces petits environnements de quelques dizaines de $\mathrm{mm}^{3}$, réducteurs et remarquablement clos. Si la pellicule péri-fécale a dû contribuer à un tel confinement, la rapidité et la densité de la précipitation de l'apatite au sein des éléments fécaux y a aussi beaucoup contribué, en isolant et en fermant l'intérieur des pellets vis-à-vis des fluides susceptibles d'entrer au contact de ses constituants.

Un accord unanime existe, par ailleurs, au sujet du rôle joué par les micro-organismes dans la mobilisation et la précipitation des ions phosphates au sein des sédiments dans des conditions sub-oxiques (Krajewski et al. 1974; Lucas et Prévôt 1984; Bréhéret 1991; Reimers et al. 1996; Hubert et al. 2005). Ces micro-organismes ont, bien sûr, un rôle essentiel tout au long de la diagenèse phosphatée lorsque le $\mathrm{P}$ est obtenu, sous l'effet de mécanismes microbiens, aux dépens des liaisons biochimiques auxquelles il appartient. Des cyanobactéries sont ainsi considérées comme responsables de la concentration du P dans le sédiment superficiel, au sein de mats grossièrement stromatolithiques et où s'initient des phénomènes de "nodulisation" conduisant aux nodules et aux péloides irréguliers observés dans de nombreux gisements (Champetier et Joussemet 1979; Lamboy 1982; Soudry 1993; Lewy 1990; Lamboy et al. 1994; Reimers et al. 1996 ; Krajewski et al. 2000). Les cyanobactéries ont aussi été reconnues comme responsables de la genèse des péloides constituant les phosphates lagonaires d'atolls (Trichet et Fikri 1997). Le P biologique (issu de molécules biochimiques et recyclé sous l'influence de micro-organismes) prend ainsi une large part à l'augmentation de la teneur en $\mathrm{PO}_{4}{ }^{3-}$ dans les solutions interstitielles (Ruttenberg et Berner 1993; Gächter et Meyer 1993; Föllmi 1996; Vink et al. 1997; Ben Hassen 2007).

Le modèle des phosphates de Ras-Draâ offre une modalité particulière à cette remobilisation générale du $\mathrm{P}$ au fond des bassins sédimentaires Si des micro-organismes benthiques ont bien recyclé, au sein du sédiment (matrices et sédiments intercalaires), du P présent dans des particules phytoplanctoniques sédimentaires selon le modèle précédent, d'autres populations 
bactériennes ont été incorporées de façon allochtone au sein du sédiment, sans y être toutefois dispersées. Il s'agit des populations du tractus intestinal des poissons qui, occluses au sein des fèces, ont transformé la matière organique intra-pellétale jusqu'à un stade humique. Privées de nouvelles sources d'énergie par l'absence d'échanges entre le pellet et son environnement extérieur les actions de dégradation et de condensation propres à ces micro-organismes ont cessé quand les produits de leur métabolisme ont atteint le stade humique.

\subsection{Implications paléogéographiques et paléo-écologiques de la sédimentation des phosphates en grains}

- $\quad$ Paléogéographie de "la mer des phosphates"

Les séries phosphatées tunisiennes appartiennent au type "transgressif", sur une plateforme épicontinentale (Sassi 1974; Föllmi 1996). Le bassin phosphaté de Gafsa-Métlaoui est localisé, à l'Yprésien, entre le môle de Kasserine et le craton méridional (ou plate-forme saharienne). Il est relié, à son extrémité orientale, à la mer ouverte (Téthys) par le détroit de Shemsi qui constituait une vanne régulatrice de l'alimentation du bassin et donc de la dynamique sédimentaire. Les fonds les plus importants de la mer yprésienne ont été localisés au Nord-Nord Ouest de la Tunisie. L'origine des eaux ayant alimenté en phosphate celles de la plateforme est recherchée dans cette mer profonde. Le caractère séquentiel de la sédimentation au sein de la série phosphatée suppose que les apports de ces eaux marines aient été, eux-mêmes, périodiques, contrôlés par des variations climatiques. Sheldon (1981) et Soudry et al. (2006) ont proposé que les courants engendrés périodiquement, au nord et le long de la plateforme tunisienne, au Paléocène-Eocène ont permis le fonctionnement d'upwellings ayant activé le transfert des éléments biogènes, notamment le $\mathrm{P}$, dans une tranche d'eau de quelques centaines de mètres d'épaisseur $(<300 \mathrm{~m})$, au droit et au profit de la plateforme. Ces courants d'upwelling, alimentant les zones superficielles en constituants nutritifs, ont conduit à une forte productivité primaire et à l'augmentation du flux du C organique atteignant les fonds marins (Belayouni 1983; Föllmi 1996). Le régime d'upwelling est favorable à la prolifération de poissons et de nombreux organismes marins essentiellement planctoniques. L'environnement de dépôt durant la phosphatogenèse était celui d'une plate forme continentale dont le climat était aride, comme il est fréquent en présence de courants d'upwelling.

- $\quad$ Paléoécologie de "la mer des phosphates" 
Le développement de la sédimentation phosphatée dans le bassin sud-tunisien, coïncide avec un accroissement de l'aridité du climat, une augmentation progressive de l'isolement du bassin et la prolifération d'un phytoplancton dans lequel dominent les dinoflagellés. Il s'agit d'un milieu marin, très peu influencé par les apports continentaux, malgré la proximité de la plate-forme saharienne émergée et de l'île de Kasserine. Le climat est aride, c'est-à-dire chaud et sec, comme en témoigne la présence d'évaporites et de faibles proportions de pollens en préparations palynologiques (Fournié 1980). Plusieurs restes de vertébrés, découverts dans les dépôts phosphatés du bassin de Gafsa-Métlaoui, indiquent des conditions marines de faible profondeur, en accord avec les données sédimentologiques. L'essentiel de ces restes, représenté par des dents, des épines, des écailleset des opercules, indique la présence de squales, de raies, des sparidés (Arambourg 1952, Noubhani et Cappetta 1997). D'après Arambourg (1952), la faune yprésienne, dans le bassin de Gafsa-Métlaoui, est dominée par des poissons marins tels quedes requins (Odontaspis macrota premut. striata; Odontaspis robusta var. africana; Odontaspis substriata atlasi; Odontaspis winkleri; Lamna obliqua; Lamna gafsana; Ginglymostoma maghrebianum; Ginglymostoma blanckenhorni; Squatirhina dartevellei; Squatirhina numidica ; Squatina prima ; Scyliorhinus subulidens ; Scyliorhinus beaugei ; Galeorhinus minor ; Physodon tertius), des raies (Eotorpedo hilgendorfi ; Rhinoptera daviesi ; Myliobatis dixoni ; Myliobatis striasus), des téléostéens (Phyllodus toliapicus; Eutrichiurides goberti; Trichiurus oshoshunensis). De même, les phosphates ont livré d'autres restes fossiles de reptiles marins tels que des serpents (Paleophis maghrebianus Aramb.) et des crocodiles (Dyrosaurus phosphaticus Thom. et Crocodylus aff. spenceri Owen), de chéloniens.

Certains éléments fauniques tels que les foraminifères et les sélaciens témoignent de milieux franchement marins. D'autres restes fossiles de requins et de raies, par exemple, indiquent une mer épicontinentale. Au total, l'environnement de dépôt des phosphates yprésiens, est donc marin, peu profond, côtier et chaud.

\subsection{Synthèse et comparaison avec d'autres gisements tunisiens et mondiaux}

L'origine et le mode de dépôt des phosphates sédimentaires relèvent de phénomènes complexes en partie mal connus. Parmi les travaux consacrés à l'étude des gisements phosphatés tunisiens, beaucoup l'ont été dans des gisements du bassin de Gafsa-Métlaoui (Sassi 1974, 1980; Belayouni 1983; Belayouni et Trichet 1983, 1984), du bassin de Sra-Ouertane (Zaier 1984), et du bassin de Meknassy-Mazzouna (Béji-Sassi 1984). Le faciès de "phosphates en grains" a été reconnu 
dans l'ensemble de ces dépôts, ainsi que les conditions diagénétiques anoxiques associées à la phosphatogenèse au sein de ces grains. Des résultats semblables ont été obtenus, dans d'autres gisements de phosphates sédimentaires, du sud de la Méditerranée (au Maroc, Rachidi 1983; Meunier-Christman 1988; Benalioualhaj 1989; en Israël, Amit et Bein 1982; Bein et Amit 1982; Nathan 1990), en Floride (Riggs 1979), ou en Australie (Sandstrom 1982, 1986). Mais même si la pétrographie en grains arrondis est reconnue dan tous ces gisements, le mécanisme de leur genèse est encore controversé. Une origine authigénique ou autochtone des pellets phosphatés s'est fondée sur des arguments sédimentologiques et biogéochimiques tels que la présence, au sein des grains de restes de constituants de la matrice, par exemple de restes de cyanobactéries (Riggs 1979; Soudry et Nathan 1980; Lamboy 1982; Soudry et Champetier 1983; Lamboy 1987, a, b; Lewy 1990; Soudry 1993). Mais de nouvelles données viennent plaider en faveur d'une origine allochtone pour les éléments phosphatés de certains gisements, à tout le moins. Telle est la thèse défendue dans cet article. Nous suggérons que les éléments à l'origine des pellets arrondis sont, pour l'essentiel, des éléments fécaux au sein desquels la diagenèse a vu l'évolution conjointe de solutions de phosphate de calcium vers des cristaux d'hydroxyapatite bien cristallisés et de matière organique d'origine planctonique (lignée II des pétroliers) vers des composés humiques. L'évolution de ces derniers a été limitée, au sein des pellets, par l'absence d'oxygène réactif dans des conditions fortement réductrices au sein des pellets.

\section{Conclusion}

La comparaison des compositions pétrographiques, minéralogiques et géochimiques des phases pellets phosphatés, matrices des pellets et sédiments de strates intercalaires - constituant les deux types de strates,les unes phosphatées ("fertiles") les autres non ou peu phosphatées ("stériles"), du gisement de Ras-Draâ montre une très grande similitude entre les sédiments dans les deux types de strates (matrices des pellets et sédiments des strates intercalaires) mais une différence catégorique entre les pellets et ces sédiments. Les sédiments sont essentiellement argilocarbonatés, souvent dolomitiques et siliceux (opale). Ils sont fossilifères et contiennent tant des macro-fossiles (dents de poissons, débris osseux) que des micro-fossiles (foraminifères, dinoflagellés). Les pellets sont restés des petits corps, fermés dès leur formation dans l'intestin de poissons leur ayant donné naissance. Ils ont alors hérité (1) d'importantes quantités de $\mathrm{P}$ et de $\mathrm{Ca}$ provenant d'une alimentation du poisson excédentaire en ces éléments (2) de quantités également substantielles de matière organique, d'origine phytoplanctonique. La décomposition microbienne 
de cette matière organique, au sein des fèces puis des pellets, transforme celle-ci en composés humiques dont l'évolution cessera précocement au sein du milieu anoxique que constitue le pellet. Les composés humiques peuvent donc être considérés comme des fossiles géochimiques, d'âge yprésien (3) la présence de microfossiles, comme des dinoflagellés, ou d'éléments de plus grande taille (fragments d'os) au sein des pellets reflète l'alimentation, non sélective, des poissons.

Cette étude mérite d'être complétée par l'acquisition de données à même de confirmer et d'élargir les résultats précédents. La géochimie et la pétrographie de la matière organique, en particulier, sont à même de fournir des informations sur l'état (ou l'étape) de la dégradation moléculaire des composés humiques qui renseigneront, à leur tour, sur la précocité plus ou moins grande de la fermeture géochimique des pellets ainsi que sur l'efficacité des associations organominérales (entre apatite et composés humiques) sur la stabilité des humus. A côté de leur signification géochimique, ces associations ont également participé à la stabilisation physique des pellets par les restes microbiens qu'elles contiennent. La RMN (Résonance Magnétique Nucléaire) est, enfin, l'outil nécessaire pour analyser le statut du $\mathrm{P}$ au sein des composés humiques. Ce phosphore est un phosphore organique, d'origine biochimique, généralement délaissé dans les bilans réalisés sur les quantités de cet élément mesurées dans des constituants sédimentaires lorsque ceux-ci contiennent d'autres phases, phosphatées minérales (apatite diagénétique ou débris osseux) ou aqueuses (P soluble), abondantes par rapport au $\mathrm{P}$ organique. 


\section{Références}

Arambourg, C. 1952: Les vertébrés fossiles des gisements de phosphates (Maroc-AlgérieTunisie). Notes et Mémoires du Service géologique du Maroc 92, 1-372.

Baioumy, H.M., Tada, R. \& Ghaeaie, M.H.M. 2007: Geochemistry of Late Cretaceous phosphorites in Egypt: Implication for their genesis and diagenesis. Journal of African Earth Sciences 49, 12-28.

Baker, K.B. \& Burnett, W.C. 1988: Distribution, Texture and Composition of modern phosphate pellets in Peru shelf muds. Marine Geology 80, 195-213.

Béji-Sassi, A. 1984: Pétrographie, minéralogie et géochimie des sédiments phosphatés de la bordure orientale de l'île de Kasserine (Tunisie). Thèse de $3^{\text {ème }}$ cycle: Géologie, Sédimentologie, Université d'Orléans, France.

Belayouni, H. 1983: Etude de la matière organique dans la série phosphatée du bassin de GafsaMétlaoui (Tunisie). Application à la compréhension des mécanismes de la phosphatogenèse. Thèse de Doctorat es-Sciences, Université d'Orléans, France.

Belayouni, H. \& Trichet, J. 1983: Preliminary data on the origin and diagenesis of the organic matter in the phosphate basin of Gafsa (Tunisia). In: Bjoroy et al., John Wiley and Sons (Eds), Advances in Organic Geochemistry 1981, 328-335.

Ben Hassen, A. 2003: Etude pétrographique et minéralogique préliminaire d'une série phosphatée tunisienne. Rapport DEA (Diplôme d'Etudes Approfondies). Université d’Orléans, France.

Ben Hassen, A. 2007: Données nouvelles sur la matière organique associée aux séries du bassin phosphaté du sud-tunisien (Gisement de Ras-Draâ) et sur la phosphatogenèse. Thèse de Doctorat, Université d'Orléans, France.

Ben Hassen, A., Trichet, J., Disnar, J.R. \& Belayouni, H. 2009: Données nouvelles sur le contenu organique des dépôts phosphatés du gisement de Ras-Draâ (Tunisie). Comptes Rendus Geosciences 341, 319-326.

Benmore, R.A., Coleman, M.L. \& McArthur, J.M. 1983: Origin of sedimentary francolite from its sulphur and carbon isotope composition. Nature 302, 516-518.

Bonel, G., Labarthe, J.C. \& Vignoles, S. 1973: Contribution à l'étude structurale des apatites carbonatées de type B. In "physico-chimie et cristallochimie des apatites d'intérêt biologique", coll. Int. CNRS, 230, 13-18. 
Bowen, S. 1981: Digestion and assimilation of periphytic detrital aggregate by Tilapia mossambica. Transactions of the American Fisheries Society 110, 239-245.

Bréhéret, J.G. 1991: Phosphatic concretions in black facies of the Aptian-Albian Marnes bleues Formation otf the Vocontian basin (SE France), and at site DSDP 369; evidence of benthic microbial activity. Cretaceous Research 12, 411-435.

Brinker, A., Koppe, W. \& Rösch, R. 2005: Optimised effluent treatment by stabilized trout faeces. Aquaculture 249, 125-144.

Cayeux, L. 1896: Note préliminaire sur la constitution des phosphates de chaux du Sénonien du sud de la Tunisie. Comptes rendus de l'Académie des Sciences, 273-276.

Cayeux, L. 1936: Existence de nombreuses bactéries dans les phosphates sédimentaires de tout âge. Comptes rendus de l'Académie des Sciences 23, 1198-1200.

Cayeux, L. 1941: Les phosphates de chaux sédimentaires de France (France métropolitaine et d'outre-mer). Tome I. Imprimerie nationale, Paris.

Chaâbani, F. 1995: Dynamique de la partie orientale du bassin de Gafsa au Paléogène. Etude minéralogique et géochimique de la série phosphatée Eocène. Tunisie méridionale. Thèse de Doctorat ès-Sciences (Géologie), Université Tunis II. Tunisie.

Champetier, Y. 1976: Localisation et approche du processus de formation de l'endogangue des phosphates en débris. Bulletin de la Société Géologique de France 7, 1017-1021.

Champetier, Y. \& Joussemet, R. 1979: Découverte de nubéculaires et d'oncolithes en tant qu'éléments phosphatés. Comptes Rendus de l'Académie des Sciences 288, 673-675.

Ece, O.I. 1990: Geochemistry and occurrence of authigenic phosphate nodules from the Desmoinesian cyclic Excello epeiric sea of the Midcontinent, USA. Marine and Petroleum Geology 7, 298-312.

Föllmi, K.B. 1996: The phosphorus cycle, phosphogenesis and marine phosphate-rich deposits. Earth-Science Reviews 40, 55-124.

Fournié, D. 1980: Phosphates et pétroles en Tunisie. Dans "Géologie comparée des gisements de phosphate et de pétrole", Document B.R.G.M 24, 157-166.

Froelich, P.N., Arthur, M.A., Burnett, W.C., Deakin, M., Hensley, V., Jahnke, R., Kaul, L., Kim, K.H., Roe, K., Soutar, A. \& Vathakanon, C. 1988: Early diagenesis of organic matter in Peru continental margin sediments: Phosphorite precipitation. Marine Geology 80, 309-343. 
Gächter, R. \& Meyer, J.S. 1993: The role of microorganisms in mobilization and fixation of phosphorus in sediments. Hydrobiologia 253, 103-121.

Garrison, R.E. \& Kastner, M. 1990: Phosphatic sediments and rocks recovered from the Peru margin during Leg 112. In: Suess E. et al. (Eds), Proc.ODP, Sc. Results 112, 111-134.

Giresse, P. 1980: The Maastrichtian Phosphate Sequence of the Congo Society of Economic Paleontologists and Mineralogists 29, 193-205.

Glenn, C.R. 1990: Pore water, petrologic and stable carbon isotopic data bearing on the origin of Modern Peru margin phosphorites and associated authigenic phases. In: Burnett W.C. and Riggs S.R. (Eds): Phosphate deposits of the world 3, 46-61.

Glenn, C.R. \& Arthur, M.A. 1988: Petrology and major element geochemistry of Peru margin phosphorites and associated diagenetic minerals : authigenesis in modern organic-rich sediments. Marine Geology 80, 231-267.

Hubert, B., Alvaro, J.J. \& Chen, J.Y. 2005: Microbially mediated phosphatization in the Neoproterozoic Doushantuo Lagerstätte, South China. Bulletin de la Société Géologique de France 176, 355-361.

Hua, K. \& Bureau, D.P. 2006: Modelling digestible phosphorus content of salmonid fish feeds. Aquaculture 254, 455-465.

Jarvis, I. 2006: The Santonian-Campanian phosphatic chalks of England and France. Proceedings of the Geologist's Association 117, 219-237.

Krajewski, P.K., Van Cappellen, P., Trichet, J., Kuhn, O., Lucas, J., Martin-Algarra, A., Prévôt, L., Tewari, V.C., Gaspar, L., Knight, R.I. \& Lamboy M. 1974: Biological processes and apatite formation in sedimentary environments. Eclogae Geologicae Helveticae 87, 701-745.

Krom, M.D. \& Berner, R.A. 1981: The diagenesis of phosphorus in a nearshore marine sediment. Geochimica Cosmochimica Acta 45, 207-216.

Lamboy, M. 1982: Importance des pelotes fécales comme origine des grains de phosphate: l'exemple du gisement de Gafsa (Tunisie). Comptes Rendus de l'Académie des Sciences 295, 595-600.

Lamboy, M. 1986: Relations entre propriétés optiques et nanostructures des grains de phosphate. Implications génétiques. Revue de Géologie dynamique et de Géographie physique 27, 311-318. Lamboy, M. 1990: Microstructures of a phosphatic crust from the Peruvian continental margin : phosphatized bacteria and associated phenomena. Oceanologica Acta 13, 439-451. 
Lamboy, M., Rao, V.P., Ahmed, E. \& Azzouzi, N. 1994: Nannostructure and significance of fish coprolites in phosphorites. Marine Geology 120, 373-383.

Lewy, Z. 1990: Pebbly phosphate and granular phosphorite (Late Cretaceous, southern Israel) and their bearing on phosphatization processes. In: A.J.G. Notholt and Ian Jarvis (Eds.): Phosphorite Research and Development. Geological Society Special Publications 52, 169-178. Louchouarn, P., Lucotte, M., Duchemin, E. \& De Vernal, A. 1997: Early diagenetic processes in recent sediments of the Gulf of St-Lawrence: phosphorus, carbon and iron burial rates. Marine Geology 139, 181-200.

Lucas, J. \& Prévöt, L. 1984: Synthèse de l'apatite par voie bactérienne à partir de matière organique phosphatée et de divers carbonates de calcium dans des eaux douces et marines naturelles. Chemical Geology 42, 101-118.

Martinez, J.I. 2003: The paleoecology of Late Cretaceous upwelling events from the Upper Magdalena Basin, Colombia. Palaios 18, 305-320.

Noubhani, A. \& Cappetta, H. 1997: Les Orectolobiformes, Carcharhiniformes et Myliobatiformes (Elasmobranchii, Neoselachii) des bassins à phosphate du Maroc (Maastrichtien-Lutétien basal). Systématique, biostratigraphie, évolution et dynamique des faunes. PalaeoIchthyologica 8, 1-327.

Reimers, C.E., Ruttenberg, K.C., Canfield, D.E., Christiansen, M.B. \& Martin, J.B. 1996: Porewater $\mathrm{pH}$ and authigenic phases formed in the uppermost sediments of the Santa Barbara Basin. Geochimica Cosmochimica Acta 60, 4037-4057.

Riggs, S. 1979: Phosphorite Sedimentation in Florida - A Model Phosphogenic System. Economic Geology 74, 285-314.

Ruttenberg, K.C. \& Berner, R.A. 1993: Authigenic apatite formation and burial in sediments from non-upwelling continental margin environments. Geochimica Cosmochimica Acta 57, 9911007.

Sandstrom, M.W. 1982: Organic Geochemistry of Phosphorites and Associated Sediments. PhD Thesis, Australian National University, Canberra.

Sassi, S. 1974: La sédimentation phosphatée au Paléocène dans le sud et le centre-ouest de la Tunisie. Thèse de Doctorat es-Sciences, Université de Paris-Orsay. France.

Sheldon, R.P. 1981: Ancient marine phosphorites. Annual Review of Earth and Planetary Science 9, 251-284. 
Slansky, M. 1980: Geology of sedimentary phosphates. North Oxford Academic, London, 210 pages.

Soudry, D. 1993: Internal Structure and Growth of an Intraformational Concretional Phosphorite from an Early Tertiary Starved-Sediment Sequence: Arava Valley, Southern Israel. Kaupia 2, 6776.

Soudry, D. \& Nathan, Y. 1980: Phosphate peloids from the Negev phosphorites. Journal of the geological Society 137, 749-755.

Soudry, D. \& Champetier, Y. 1983: Microbial proceses in the Negev phosphorites (southern Israel). Sedimentology 30, 411-423.

Soudry, D., Glenn, C.R., Nathan, Y., Segal, I. \& Vonderhaar, D. 2006: Evolution of Tethyan

phosphogenesis along the northern edges of the Arabian-African shield during the CretaceousEocene as deduced from temporal variations of $\mathrm{Ca}$ and $\mathrm{Nd}$ isotopes and rates of $\mathrm{P}$ accumulation. Earth-Science Reviews 78, 27-57.

Storebakken, T. 1985: Binders in fish feeds I. Effect of alginate and guar gum on growth, digestibility, feed intake and passage through the gastrointestinal tract of rainbow trout. Aquaculture 58, 11-26.

Storebakken, T. \& Austerng, E. 1987: Binders in fish feeds II. Effect of different alginates on the digestibility of macronutrients in Rainbow trout. Aquaculture 60, 121-131.

Trichet J. \& Fikri A. 1997: Organic matter in the genesis of high-island atoll phosphorites : the lagoonal link. Journal of Sedimentary Research 67, 891-897.

Vink, S., Chambers, R.M. \& Smith, S.V. 1997: Distribution of phosphorus in sediments from Tomales Bay, California. Marine Geology 139, 157-179.

Visse, L. 1974: Sédimentologie: Précisions sur la paléosédimentation phosphatée marine. Comptes Rendus de l'Académie des Sciences 278, 585-588.

Wotton, R.S. \& Malmqvist, B. 2001: Feces in Aquatic Ecosystems. BioScience 51, 537-544.

Zaier, A. 1984: Etude stratigraphique et tectonique de la région de Sra Ouertane (Atlas tunisien central). Lithologie, pétrographie et minéralogie. Thèse de Doctorat de $3^{\text {ème }}$ cycle, Université de Tunis, Tunisie. 


\section{Planche 1 : Observations de la structure de pellets phosphatés et de leurs matrices}

Photo 1 : Observation à la loupe binoculaire de pellets phosphatés, extraits de la couche II de la série de Ras-Draâ. Remarquer les formes globalement arrondies à ovoïdes, dérivées pour beaucoup de formes cylindriques (voir photo 2). Les teintes externes des grains sont blanc-grises ou brunâtres. Quelques grains (étoile noire) montrent d'anciennes empreintes de contact entre ces grains et des grains voisins, au niveau desquelles l'absence de la pellicule claire, blanc-grise (voir photo 3) montre la couleur brune de l'intérieur du pellet.

Photo 2 : Observation à la loupe binoculaire de pellets phosphatés montrant des morphologies cylindriques, généralement attribuées à des pelotes fécales. Les cortex clairs témoignent de la présence d'une pellicule phosphatée à la périphérie de ces grains, recouvrant le corps du pellet dont la couleur fondamentale est brune.

Photo 3: Observation à la loupe binoculaire de pellets phosphatés montrant des cortex clairs parsemés de taches brunes correspondant à des alvéoles d'attachement d'autres petits pellets.

Photo 4 : Observation microscopique de grains phosphatés de la couche VII de la série de RasDraâ et de leur matrice. Plusieurs grains (étoile blanche) ont un mince cortex blanc-gris apparaissant sous la forme d'une pellicule d'épaisseur $<5 \mu \mathrm{m}$. D'autres grains (cercle blanc) ont perdu cette pellicule. L'exogangue est essentiellement dolomitique.

Au centre de l'image la matière d'un grain phosphaté se disperse au sein de la matrice. Ce processus a conféré à celle-ci une teneur en $\mathrm{P}_{2} \mathrm{O}_{5}$ de l'ordre de 5.80\%.

Photo 5 : Observation microscopique de grains phosphatés de la couche VIII de la série de RasDraâ. Certains grains montrent une structure concentrique en leur sein. Les deux grains situés en bas de la photo ont conservé une partie de leur pellicule initiale.

Photo 6 : Observation microscopique de grains phosphatés de la couche V de la série de RasDraâ. Plusieurs grains possèdent des restes irréguliers de la pellicule claire ayant entouré initialement le pellet. La MO apparaît, soit dispersée au sein des pellets, soit concentrée dans le cœur de ceux-ci et au droit de particules irrégulières, noires, de quelques dizaines de micromètres de dimension moyenne (carré blanc). Le contour sub-circulaire du pellet (triangle blanc) visible en bas de l'image et s'interrompant dans la partie Nord-Ouest de celui-ci témoigne du début de la dispersion de son contenu au sein de la matrice. 


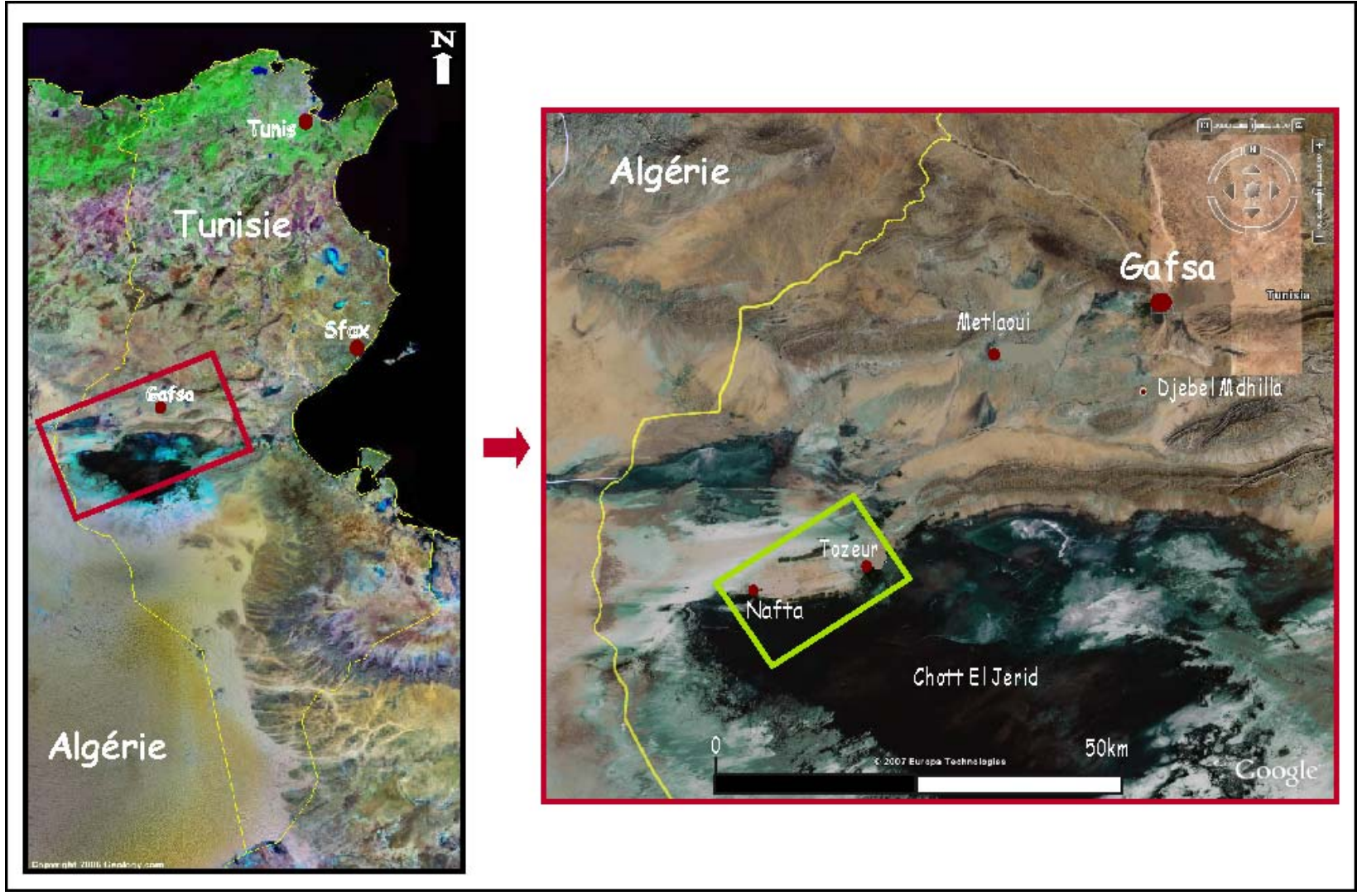




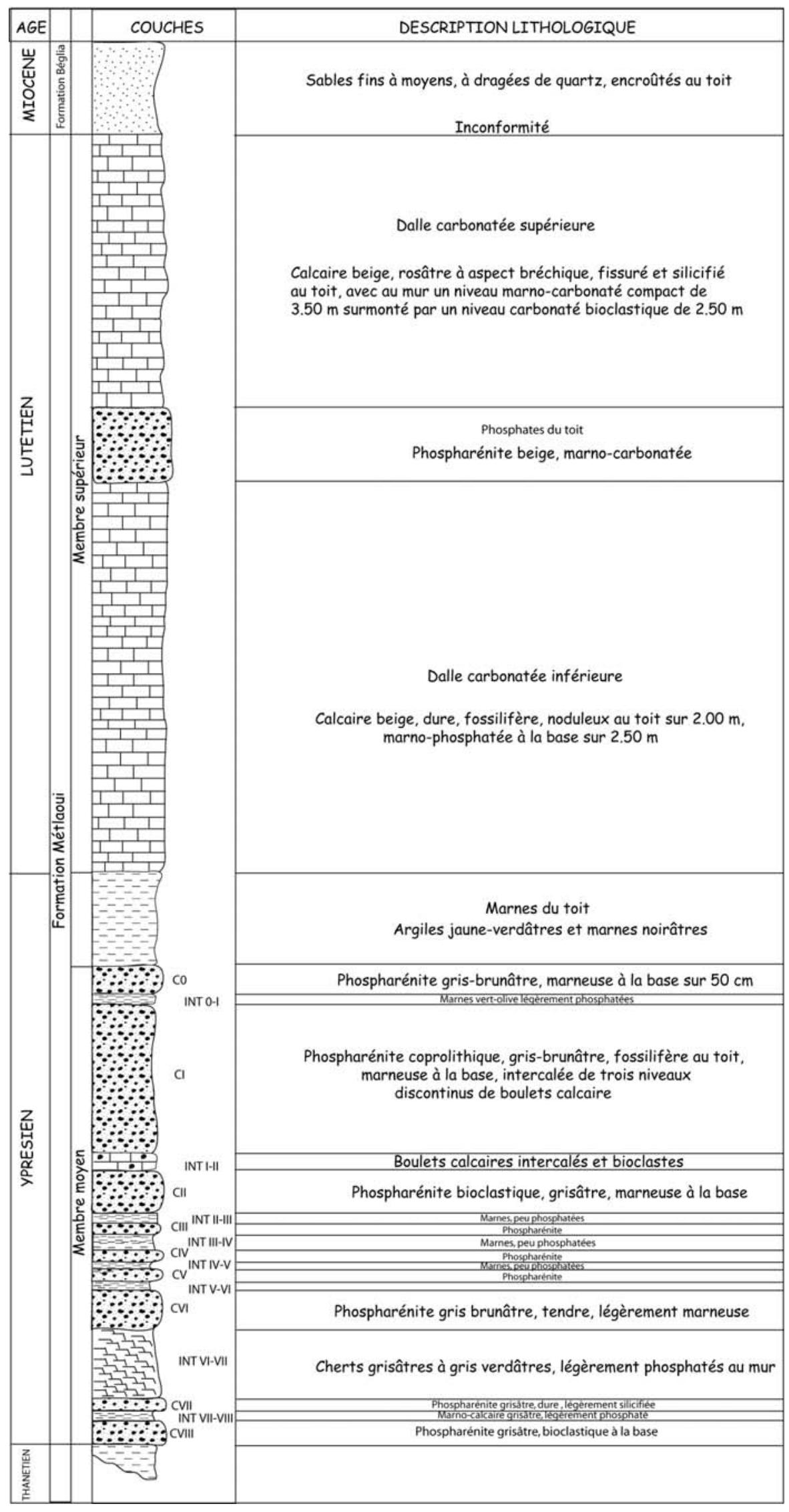



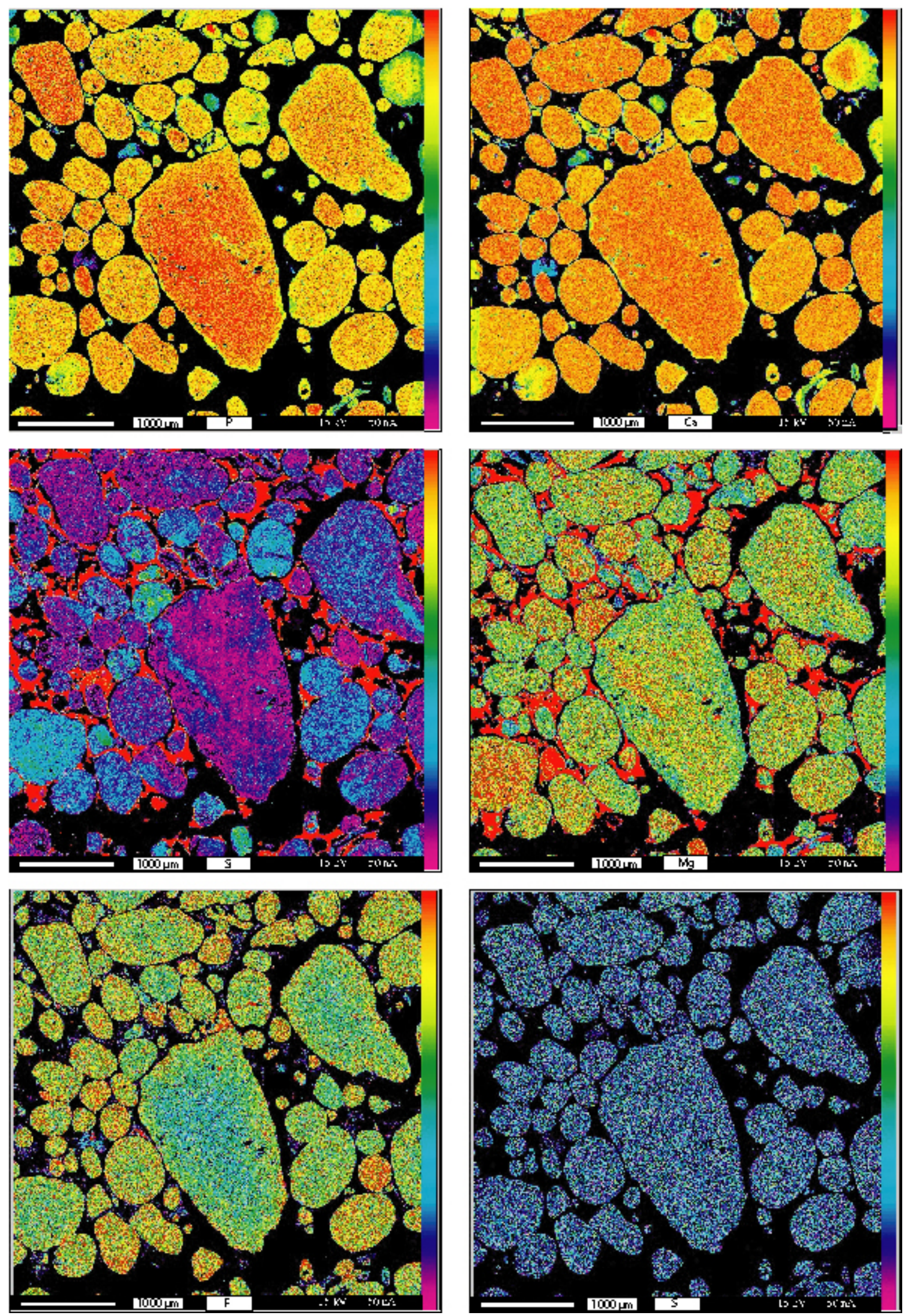
Planche 1
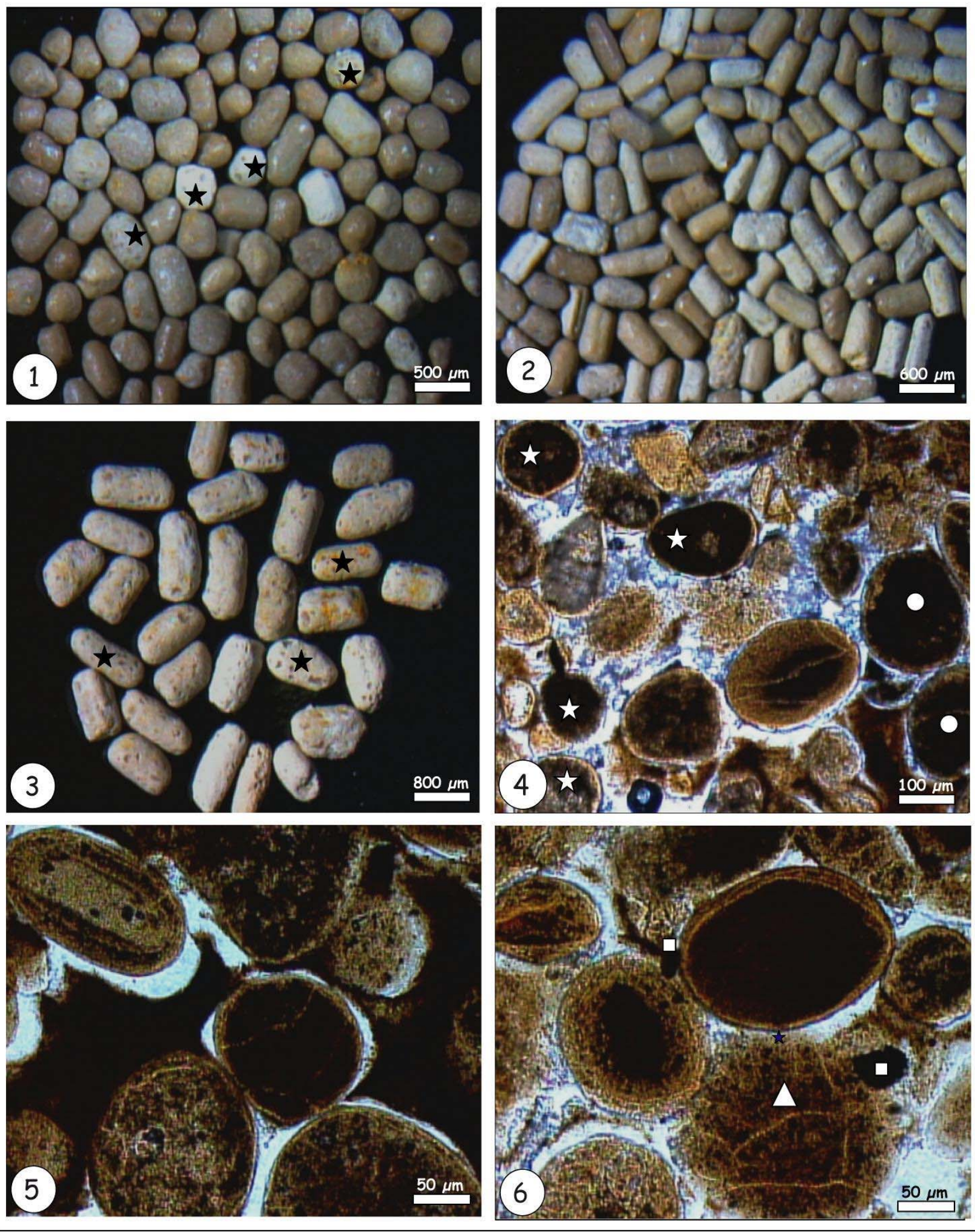


\begin{tabular}{|c|c|c|c|c|c|c|c|c|c|c|c|}
\hline & $\mathbf{P}_{2} \mathbf{O}_{5}$ & $\mathrm{SiO}_{2}$ & $\mathrm{TiO}_{2}$ & $\mathbf{A l}_{2} \mathbf{O}_{3}$ & $\mathrm{Fe}_{2} \mathbf{O}_{3}$ & MgO & MnO & $\mathrm{CaO}$ & $\mathrm{Na}_{2} \mathrm{O}$ & $\mathbf{K}_{2} \mathbf{O}$ & $\begin{array}{l}\text { Perte } \\
\text { au feu }\end{array}$ \\
\hline CI Pellets & 38,31 & 3,11 & 0,04 & 0,58 & 0,07 & 0,34 & 0,01 & 59,89 & 1,31 & 0,08 & 9,68 \\
\hline CII Pellets & 32,69 & 1,63 & 0,04 & 0,55 & 0,11 & 0,57 & 0,00 & 54,87 & 1,33 & 0,05 & 11,17 \\
\hline CIII Pellets & 30,32 & 1,55 & 0,04 & 0,55 & 0,20 & 0,40 & 0,01 & 51,16 & 1,33 & 0,06 & 11,55 \\
\hline CIV Pellets & 30,09 & 1,93 & 0,05 & 0,67 & 0,20 & 0,46 & 0,01 & 52,05 & 1,31 & 0,07 & 12,50 \\
\hline CV Pellets & 30,05 & 3,33 & 0,05 & 0,75 & 0,31 & 0,53 & 0,01 & 49,22 & 1,39 & 0,07 & 11,23 \\
\hline CVI Pellets & 30,23 & 2,18 & 0,05 & 0,71 & 0,50 & 0,43 & 0,01 & 50,40 & 1,30 & 0,06 & 11,11 \\
\hline CVII Pellets & 30,23 & 3,00 & 0,04 & 0,69 & 0,27 & 0,60 & 0,01 & 50,60 & 1,40 & 0,06 & 11,33 \\
\hline CVIII Pellets & 28,41 & 3,65 & 0,04 & 0,75 & 0,16 & 0,60 & 0,01 & 50,79 & 1,71 & 0,15 & 11,22 \\
\hline CI Matrice & 5,17 & 34,74 & 0,36 & 9,78 & 2,26 & 2,46 & 0,02 & 20,70 & 0,30 & 2,35 & 19,96 \\
\hline CII Matrice & 12,49 & 24,66 & 0,23 & 6,53 & 1,93 & 3,59 & 0,01 & 30,35 & 0,64 & 0,78 & 18,48 \\
\hline CIII Matrice & 9,07 & 32,61 & 0,29 & 8,32 & 2,40 & 3,10 & 0,02 & 21,18 & 0,52 & 0,97 & 18,68 \\
\hline CIV Matrice & 2,70 & 17,54 & 0,16 & 4,56 & 2,49 & 2,00 & 0,01 & 35,38 & 0,28 & 0,64 & 33,30 \\
\hline CV Matrice & 6,09 & 44,09 & 0,29 & 6,39 & 2,19 & 3,17 & 0,02 & 13,31 & 0,55 & 0,54 & 18,54 \\
\hline CVI Matrice & 3,64 & 41,41 & 0,43 & 10,11 & 4,27 & 4,31 & 0,02 & 9,90 & 0,40 & 0,64 & 21,97 \\
\hline CVII Matrice & 5,80 & 43,57 & 0,27 & 6,07 & 2,02 & 5,16 & 0,02 & 13,45 & 0,37 & 0,44 & 20,81 \\
\hline CVIII Matrice & 7,64 & 24,35 & 0,28 & 5,67 & 2,60 & 2,72 & 0,01 & 28,91 & 0,60 & 0,70 & 23,22 \\
\hline INT 0-I & 0,91 & 43,36 & 0,54 & 13,26 & 6,34 & 6,15 & 0,02 & 8,18 & 0,27 & 1,07 & 21,65 \\
\hline INT I-II & 14,52 & 21,96 & 0,21 & 6,10 & 1,24 & 2,83 & 0,01 & 33,50 & 0,64 & 1,32 & 17,33 \\
\hline INT II-III & 1,10 & 42,97 & 0,43 & 10,90 & 3,30 & 6,50 & 0,03 & 10,15 & 0,29 & 0,69 & 23,16 \\
\hline INT III-IV & 0,83 & 38,86 & 0,49 & 11,40 & 3,99 & 7,08 & 0,03 & 10,69 & 0,29 & 0,72 & 25,29 \\
\hline INT IV-V & 1,17 & 37,22 & 0,53 & 11,82 & 4,60 & 6,70 & 0,02 & 8,60 & 0,24 & 1,66 & 24,17 \\
\hline INT VI-VII & 0,86 & 55,52 & 0,17 & 3,57 & 1,21 & 6,28 & 0,02 & 8,88 & 0,63 & 0,36 & 19,49 \\
\hline INT VII-VIII & 2,00 & 32,74 & 0,31 & 7,87 & 3,08 & 6,04 & 0,02 & 22,06 & 0,48 & 0,56 & 26,33 \\
\hline
\end{tabular}




\section{Liste des tableaux et figures}

Tableau 1 : Composition chimique des pellets phosphatés et de leurs matrices, séparés dans les strates de la série phosphatée de Ras-Draâ et des sédiments des strates "stériles". \% pondéraux. CI pellets : pellets isolés de la couche I phosphatée. CI matrice : matrices des pellets dans la couche I phosphatée. INT I-II : sédiment intercalaire entre les couches I et II.

Figure 1 : Carte de localisation du gisement phosphaté de Ras-Draâ dans le bassin de Gafsa-Métlaoui (Tunisie) (source : www. googleearth.com). Le rectangle rouge localise le bassin phosphaté de GafsaMétlaoui et le rectangle vert localise le gisement de Ras-Draâ.

Figure 2 : Profil lithostratigraphique de la série phosphatée du gisement de Ras-Draâ.

Figure 3 : Répartition des éléments chimiques $(\mathrm{P}, \mathrm{Ca}, \mathrm{Si}, \mathrm{Mg}, \mathrm{F}, \mathrm{S})$ à la surface d'une section polie d'un échantillon phosphaté brut (Couche VII) de la série de Ras-Draâ. Microsonde électronique. Echelles des concentrations (en $\mu \mathrm{g} / \mathrm{g})$ : P (20-1150), Ca (200-1600), Si (20-200), Mg (20-50), F (2-12), S (2-8). 